\title{
A small Askin's tumor presenting with early onset of chest pain
}

\author{
Jin Yong Jeong ${ }^{1}$, Sang Yong Kim²*, Dae Chul Jeong ${ }^{3}$ and Ki Jun $\mathrm{Kim}^{4}$
}

\begin{abstract}
Most primitive neuroectodermal tumor of the chest wall destroy the rib, chest wall muscles, diaphragm, and lung or extend into the spinal compartment, resulting in a large-sized tumor and symptoms. In contrast, we recently encountered a rare case of Askin's tumor presenting with early-onset chest pain despite the small size. After resection of the tumor and adjuvant chemotherapy, the patient remains disease-free over 3 years of follow-up.
\end{abstract}

Keywords: Primitive neuroectodermal tumor, Askin's tumor, Chest wall

\section{Correspondence}

We read with great interest the article by Benbrahim et al. [1], which reported two cases of rare primitive neuroectodermal tumor (PNET) developing from the soft tissues of the chest wall (Askin's tumor). The chest radiograph and computed tomography $(\mathrm{CT})$ of the cases revealed the tumor destroyed the rib cage. The patients received polychemotherapy and one of them surgical resection. We agree that Askin's tumor is very aggressive and need multimodal treatment, because of the poor prognosis with a high recurrent rate. Recently, we encountered a small Askin's tumor with early-onset chest pain and present herein.

A 14-year-old girl presented with chest pain. Chest radiograph showed a small nodular opacity in the right lung field, suggesting focal pneumonia or mass, and CT scan revealed a small mass with a broad base on the pleura of the right anterior hemithorax and pleural effusion (Figure 1). We resected the mass for the diagnostic and therapeutic purposes. The pathology and immunohistochemistry of the tumor coincided with PNET which was classified as stage IA(T1aNOMOGX). She received six courses of adjuvant chemotherapy including vincristine, etoposide, doxorubicin, cyclophosphamide, and ifosfamide with mesna. She had been tolerable during chemotherapy, achieved complete response, and has been well without recurrence 3 years thereafter.
Peripheral PNET outside the central nervous system has an insidious onset of symptoms. Askin's tumor destroys the rib and often extends into the spinal, retroperitoneal, and intrathoracic compartments, resulting in symptoms and a large-sized tumor $(>5 \mathrm{~cm}$ on average) $[2,3]$. In contrast, the presenting case is a small-sized Askin's tumor presenting with early-onset chest pain, which was thought to be caused by the involvement of the parietal pleura. Unfortunately, there is currently no means to early detect an asymptomatic Askin's tumor. From our case, even a small-sized PNET might cause symptoms. We believe that meticulous examination with $\mathrm{CT}$ and/or positron emission tomography and the suspicion of Askin's tumor prior to surgery is important.

\section{Consent}

Written informed consent was obtained from the patient's parent for the publication of this report and any accompanying images.

\footnotetext{
* Correspondence: sykim2010@catholic.ac.kr

²Department of Pediatrics, Incheon St. Mary's Hospital, College of Medicine, The Catholic University of Korea, 222 Banpo-Daero, Seocho-Gu, Seoul 137-7, South Korea

Full list of author information is available at the end of the article
}

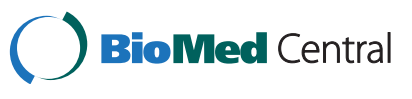

(c) 2015 Jeong et al.; licensee BioMed Central. This is an Open Access article distributed under the terms of the Creative Commons Attribution License (http://creativecommons.org/licenses/by/4.0), which permits unrestricted use, distribution, and reproduction in any medium, provided the original work is properly credited. The Creative Commons Public Domain Dedication waiver (http://creativecommons.org/publicdomain/zero/1.0/) applies to the data made available in this article, unless otherwise stated. 


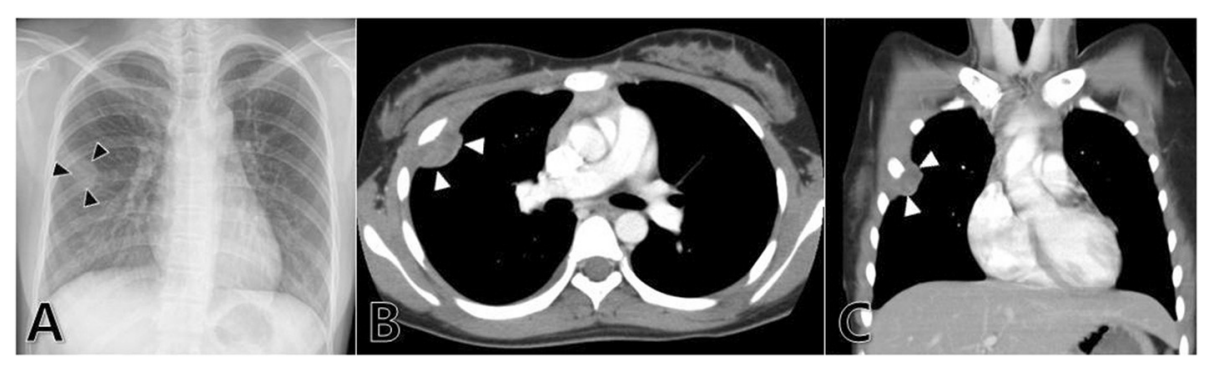

Figure 1 CT scan revealing a small mass with a broad base. A small nodular opacity (black arrowheads) in the right chest on chest radiograph $(\mathbf{A})$ revealed a mass $(2.7 \times 2.2 \mathrm{~cm}$ in size) on the pleura of the right anterior hemithorax (white arrowheads) with irregular soft tissue density and inner heterogeneous enhancement on $C T$ scan (B) and (C)

\section{Abbreviations}

CT: computed tomography; PNET: primitive neuroectodermal tumor.

\section{Competing interest}

The authors declare that they have no competing interest. Furthermore, there is no funding for each author and for the manuscript preparation.

\section{Authors' contributions}

All authors carried out this work in collaboration. JYJ and SYK reviewed the medical records and wrote the manuscript. DCJ participated in reviewing the scientific literature and contributed to the final version of the manuscript. KJK have been involved in the acquisition of clinical data. JYJ, SYK, DCJ, and KJK created the study materials or recruited the patient. All authors read and approved the final manuscript.

\section{Acknowledgements}

We thank Linda $\mathrm{H}$ who provided English medical writing services on behalf of HARRISCO.

\section{Author details}

'Department of Thoracic and Cardiovascular Surgery, Incheon St. Mary's Hospital, College of Medicine, The Catholic University of Korea, 222 Banpo-Daero, Seocho-Gu, Seoul 137-701, South Korea. ${ }^{2}$ Department of Pediatrics, Incheon St. Mary's Hospital, College of Medicine, The Catholic University of Korea, 222 Banpo-Daero, Seocho-Gu, Seoul 137-7, South Korea. ${ }^{3}$ Department of Pediatrics, Seoul St. Mary's Hospital, College of Medicine, The Catholic University of Korea, 222 Banpo-Daero, Seocho-Gu, Seoul 137-701, South Korea. ${ }^{4}$ Diagnostic Radiology, Incheon St. Mary's Hospital, College of Medicine, The Catholic University of Korea, 222 Banpo-Daero, Seocho-Gu, Seoul 137-701, South Korea.

Received: 19 August 2014 Accepted: 9 February 2015 Published online: 15 March 2015

\section{References}

1. Benbrahim Z, Arifi S, Daoudi K, Serraj M, Amara B, Benjelloun MC, et al. Askin's tumor: a case report and literature review. World J Surg Oncol. 2013;11:10-3.

2. Hari S, Jain TP, Thulkar S, Bakhshi S. Imaging features of peripheral primitive neuroectodermal tumours. Br J Radiol. 2008;81:975-83.

3. Sallustio G, Pirronti T, Lasorella A, Natale L, Bray A, Marano P. Diagnostic imaging of primitive neuroectodermal tumour of the chest wall (Askin tumour). Pediatr Radiol. 1998;28:697-702.

\section{Submit your next manuscript to BioMed Central and take full advantage of:}

- Convenient online submission

- Thorough peer review

- No space constraints or color figure charges

- Immediate publication on acceptance

- Inclusion in PubMed, CAS, Scopus and Google Scholar

- Research which is freely available for redistribution 